\title{
Research on Problems and Measures of Energy- Saving in Electric Power
}

\author{
Xin Cheng \\ Shenyang Environmental Monitoring Center \\ Shenyang, China \\ chengx@163.com
}

\begin{abstract}
Thermal power enterprises as the backbone of China's power industry, which relies on the conversion of thermal energy to produce clean electricity, while heat production is an energy consuming process. Implementation of emission reduction is to implement the scientific development and building a harmonious socialist society major initiatives is the inevitable choice to achieve sustainable development. Through a comprehensive analysis of the national energy saving and power situation, put the power industry the importance of energy conservation and emission reduction pathways analyzed several problems existing in China's energy conservation work, noting that by adjusting the layout of the power industry, strengthen scientific research and technical means to adjust the work of the three measures, the final recommendations summarized several aspects.
\end{abstract}

Keywords- electric power; energy-saving; problem; measure

\section{INTRODUCTION}

In recent years, global warming has become one of the most serious challenges facing humanity in the 21 st century. Global warming will lead to melting glaciers, rising sea levels and natural disasters, the depth of the impact on agriculture and food security, ecological security, public health security and energy security, a direct threat to human survival and development[1-2]. The emissions of greenhouse gases from human activities is increasing is the most important trigger of global warming. At present, it has been found in the atmosphere to produce greenhouse gases nearly 30 kinds, including $\mathrm{C} 02$ plays an important role. In the global warming effect of greenhouse gases caused, $\mathrm{C} 02$ effect up to $77 \%$. Therefore, to reduce $\mathrm{C} 02$ emissions, is an important issue to be solved.

Sustainable development means that both meets the needs of the present without compromising the ability of future generations to meet demand, and energy conservation refers to save energy consumption and reduce pollution, promote environmental protection, sustainable development and energy conservation and therefore have a very strong interconnectedness. Energy conservation is an important aspect of sustainable development; the core of sustainable development is development, but requires strict control of population, improve quality and protect the environment, under the premise of sustainable use of resources through energy conservation and other specific ways, conduct economic and social development[3-6].

The rapid growth of social progress and economic conflict between economic development and resources and the environment has become increasingly acute problem pollutant emissions and energy consumption is also growing. Because of the market mechanism is not perfect, it is necessary to resolve the current conflict between the environment and economic resources, but also to promote economic development, the task is arduous, the situation is complicated. As soon as possible if you do not adjust the economic structure, transform the mode of growth, sustainable economic development will be difficult to sustain. Power industry is an important support economic and social development, with the growing size of the electric power industry, and its own energy consumption and pollution emissions are also increasingly prominent. The Chinese government attaches great importance to energy conservation and pollution reduction, "Eleventh Five-Year Plan" will "unit GDP energy consumption reduction" and "total pollutant emission reduction" as a binding target[7]. Basic electricity as a secondary energy, is an important blood of modern economic life, the importance of self-evident. Electricity is the basis of the country's energy industry, large-scale thermal power plants as a clean energy producers, but it is also energy-hungry, plays an important social responsibility in the field of Energy-Saving and environmental protection, has become the focus areas of the national energy-aving. In recent years, extremely rapid development of China's power industry. With the constant improvement to improve national energy policy and environmental policy, although the proportion of coal-fired power will be reduced, hydropower, nuclear power, wind power and other new energy power generation will be increased, but at a certain time is difficult to change, and the total will rise. Therefore, the power industry, especially power plants actively implement energy conservation is critical.

\section{WAY OF ENERGY-SAVING IN ELECTRIC POWER}

Ways to implement energy conservation include three types: system management tools, technological innovation means change and adjustment of industrial structure for energy conservation, to the technical, structural, institutional efforts, the comprehensive implementation of energy conservation. According to our national conditions and foreign experience, 
mainly for energy conservation from the market mechanism, technology, industrial structure adjustment.

\section{A. Market mechanisms}

According to international experience and China's national conditions of energy conservation, coupled with the market mechanism to promote sustainable development policy mechanisms (market mechanisms and government macroeconomic regulation), effective regulation and energyaving technical support system, an effective energy conservation policy, together constitute a long-term energyaving mechanism to promote energy conservation. The market mechanism is through competition, give full play to the market in allocating resources to the basic role in enhancing the efficiency of resource allocation; the market mechanism is to establish long-term mechanism of energy-aving basic institutional arrangements. However, the market mechanism itself can not completely solve the problem of externalities such as energy conservation, environmental protection, etc., must be oriented to promote sustainable development of policy mechanisms, to make up for the lack of market mechanisms in the energy-aving. China is in a planned to a market economy transition from a planned economy and the coexistence of twotrack phase of the market, the role of market mechanisms in the energy-aving in full yet, designed to meet the required conditions of the market mechanism. Policy mechanisms to promote sustainable development through the development and implementation of laws, regulations, standards, prices, finance, taxation, banking, and other integrated policies to promote government, business, public shift from passive energy-aving energy-aving initiative; promoting Policy mechanisms for sustainable development is to achieve energy reduction targets comprehensive institutional arrangements. Regulatory mechanisms for implementing the national energy conservation policy supervision of the relevant parties, including energyaving, environmental protection, resource efficiency, social regulation and market structure (and prevent the abuse of market power) and other economic regulation. Energy-aving technical support system, including technological innovation and promote the use of energy-aving, energy-aving and technical support system transactions, supervision and monitoring of energy consumption and pollutant emissions technology support systems, energy conservation index evaluation and assessment of technical support systems. In the early work to promote energy conservation, structural and institutional contribution to the total energy-aving energy-aving emission reduction rate of about $70 \%$, is the primary way to achieve emission reduction targets; in the latter part of the work to promote energy conservation, the main energy conservation work carried out by the system (or management) tools and techniques.

\section{B. Technical}

Electric power industry to promote scientific and technological progress is the development of a powerful driving force, to improve the quality of economic power, narrowing the gap with the international advanced level, one important way is to apply modern science and technology to improve the level of electricity production and management modernization, enterprise management science, intensive, fine.
Environmental protection, resource use and economic coordination, the formation of healthy development system structure, increase the development of clean energy through source control method to achieve the standard rid effect, in particular, energy consumption unreasonably strict source control, energy conservation and economic development persist in unison; fully implement the scientific concept of development, to ensure economic development and energy conservation targets in unison each region; relying on science and technology, and increase efforts to develop energy-aving technologies; energy reduction in power generation, transmission and distribution of electricity in the whole process of implementation; intensify propaganda, raise public to reduce pollution emissions in the energy production of consciousness.

An electric power companies from the initial project planning, engineering design started from the design of main and auxiliary equipment selection, system control strategy development; control the debugging process; initial production crew safe and stable operation; production and use in the process of operation and maintenance and post-commissioning crew equipment modification, adjustment and optimization run, every aspect of each stage contains numerous key technologies, thus affecting the efficiency of the technical means of the unit is self-evident. Electricity is equipment industry, engineering design once completed, its energy consumption and emission levels basically OK. If there is insufficient design, operational efficiency will be long-term effects, re-transformation will result in new losses. Therefore, the design process of strict control, and select the critical process systems and technologies. Engineering design phase, selection, parameter selection and optimization of integrated generators, as well as water, drainage, desulphurization, dust and other auxiliary systems to optimize the design and selection, will directly affect the unit's operational safety and economy. After commissioning the power companies do a good job security and stable operation of the unit, to improve the technical level of business operation and management staff, really good run adjustment, equipment modification, to ensure safe and economic operation of the unit Can take a variety of measures to reduce environmental emissions, such as the use of low-sulfur coal, install desulfurization equipment, the use of low NO $\mathrm{x}$ burners, install denitrification devices, such as electrostatic precipitators installed to reduce pollutant emissions.

Electric power industry to promote scientific and technological progress is the development of a powerful driving force, to improve the quality of economic power, narrowing the gap with the international advanced level, one important way is to apply modern science and technology to improve the level of electricity production and management modernization, enterprise management science, intensive, fine. Environmental protection, resource use and economic coordination, the formation of healthy development system structure, increase the development of clean energy through source control method to achieve the standard rid effect, in particular, energy consumption unreasonably strict source control, energy conservation and economic development persist in unison; fully implement the scientific concept of development, to ensure economic development and energy conservation targets in unison each region; relying on science 
and technology, and increase efforts to develop energy-aving technologies; energy reduction in power generation, transmission and distribution of electricity in the whole process of implementation; intensify propaganda, raise public to reduce pollution emissions in the energy production of consciousness.

\section{Adjustment of industrial structure}

Power macro planning for the development of the industry plays a decisive role, we should be careful planning, strict system or revised standards and sum up the experience of the implementation process, in order to promote the sustainable development of the power industry. According to China's energy, load centers and distribution of electric power enterprises, research resource optimization program, reasonable arrangements for the flow and distribution of energy, control of power losses during transport; and optimize the structure of coal-fired power generation, construction, energy efficient units, local conditions to develop cogeneration . With the continuous improvement of national energy policy and environmental policy improvements, adjustment of industrial structure, improve hydropower, nuclear power, wind power and other renewable energy utilization, which will be an important way of energy-aving electricity. At the same time, take administrative measures to intervene and short and long term means of deepening the reform of the power, under the pressure of market competition, but also will promote the power companies to optimize the allocation of resources to maximize and improve production efficiency, promote conservation and development to better and faster to achieve emission reduction targets.

\section{PROBLEM OF ENERGY-SAVING IN ELECTRIC POWER}

State energy conservation work has always attached great importance to the State Council promulgated a special program not only for the different characteristics of all walks of life also formulate corresponding policies and regulations. However, the implementation of energy conservation, power stage still rely mainly on administrative laws and regulations, etc., to promote energy conservation efforts through the market mechanism is not enough, and did not play an active role in the combination of various measures. Therefore, research and the establishment of long-term mechanism of power energy conservation, the use of legal and market mechanisms interact to ensure long-term emission reduction targets better and faster to complete.

Under the influence of the market environment, the price of electricity and fuel (coal) prices directly affect the economic benefits of electric power enterprises, especially thermal power enterprises. In recent years, with the rise in the price of coal, water and sewage charges, the effectiveness of thermal power enterprises grim. In the current market environment conditions, which account for a large proportion of thermal power enterprises, economic suffering and coal prices directly affect the price. With the rising price of coal and sewage charges increase, water resources and other cost increases, thermal power enterprises grim economic situation. Especially in the past two years, prices for coal thermal power companies to bring serious pressure on energy-saving emission reduction targets resulting in a greater impact. Fired power plants in the energy mainly coal, resulting in the selection point in the process the cost of coal as the focus, thus ignoring the carrying capacity of the environment, thermal power enterprises flocks phenomenon has caused air pollution in some areas, destroyed ecological plant areas.

Energy conservation research and development of new technology has made some achievements, direct air cooling unit, desalination, water reuse and a number of successful application of new technologies, largely reduce the power consumption and reduced business pollution emissions. However, the whole power of technology to improve business a lot of work to do, ranging from three host selection, adjust and optimize the operation mode parameters, power consumption rate and reduce line losses, optimizing each auxiliary systems, small consumption of each device, including a large number of technical issues, we also need to carry out a full range of diagnostic and continuous improvement of performance in order to improve China's electric power industry's overall technological level.

\section{MEASURES OF ENERGY-SAVING IN ELECTRIC POWER}

\section{A. Electricity restructuring}

Under the appropriate technical and economic conditions, the active use of $600 \mathrm{MW}$ and one million kilowatts ultrasupercritical, ultra-supercritical pressure parameters, large capacity, high efficiency, high regulatory units, so the proportion of $300 \mathrm{MW}$ and above thermal power units gradually dominant, while speed up shutting down inefficient, highpolluting, non-condensing steam pure economy of small thermal power units; actively develop clean coal combustion technology, adequate, efficient and clean use of low-quality coal resources; continue to develop thermoelectric (cold) and power unit, improving energy Integrated conversion efficiency. Power grid construction, speed up regional and provincial transmission grid frame construction, improve resource utilization efficiency and inter-regional power grids and electric power and energy exchange between the provincial power grid and mutual support, play a major power in the standby electricity consumption Freemasons, complementary water and fire benefits and other aspects; at the same time, strengthen the construction of urban and rural power grid, power and coordination to achieve grid, transmission and distribution of synchronous development. In large power stations and power grids to ensure the supply of basic situation, while supporting the development of distributed energy systems, to play its flexible load characteristics, low investment, high reliability, low transmission loss and can be characterized by the use of renewable energy, protection of important user electricity supply, improve energy efficiency.

The proportion of the electricity industry is far greater than other aspects of electricity use, rapid industrial development is the fundamental reason for the rapid growth of electricity consumption. To suppress the rapid growth of electricity use, it is necessary from the facts of rapid industrial development starting, through the adjustment of industrial structure to solve the high power and energy industry issues. Blindly led to the establishment of thermal power plant coal supply and demand imbalance, and extreme pollution of the local environment. To achieve the goal of energy-saving environmental protection, it 
is necessary to avoid the establishment of thermal power enterprises disorder. Only starting from the source of the problem, a reasonable plan to solve the problem fundamentally.

\section{B. Transformation}

To continue on the main device by a non-elimination units and important auxiliary energy system transformation, through the use and improvement of operational monitoring and optimization tools, condition-based maintenance technology to improve the management level and the level of modernization of the plant's production automation; promotion of mechanical, electrical, furnace integrated control technology and plant-level automation systems; powder monitored by the wind, and improve economic soot blowing and online analysis system, so that timely operation adjustment; $100-300 \mathrm{MW}$ steam turbine for high, medium and low-pressure cylinder circulation section for energy transformation; frequency control and other advanced motor adjustment technology to reduce power consumption rate.

\section{Strengthening scientific research}

Energy conservation is a huge project, research is its solid foundation. After the electric power system, energy-aving and emission reduction management system, monitoring and supervision system disintegrated, were placed under the relevant research institutions, restructuring of the power grid, power generation enterprise technology companies within the group. Although to some extent, an increase of some companies for their research capacity and technological development capability, but overall, the global power industry for the development of a comprehensive, systematic, timely research capacity has been significantly weakened.

\section{CONCLUSION}

Thermal power enterprises as the backbone of China's power industry, which relies on the conversion of thermal energy to produce clean electricity, while heat production is an energy consuming process. Energy consumption is a major thermal power plant coal into electricity in its process, will produce a variety of environmental pollution resulting gases which cause acid rain, the greenhouse effect and so on. The power industry to truly achieve energy reduction targets, it is necessary to improve the long-term mechanism of energy conservation, the use of laws and regulations and market-based instruments combine assist countries to increase the macro planning, adjust the overall structure of the power industry, so electricity industry structure and scientific, while strengthening the control of emissions of polluting gases and to develop appropriate laws and regulations, strict supervision and careful execution. Thus, in order to truly suppress emissions-fired power plants, in order to solve the problem at the source, in order to achieve faster and better energy conservation targets.

\section{REFERENCES}

[1] A. Poole, H. S. Geller, "Energy A. C. The Emerging Esco Industry in Brazil," AmericanCouncil for an Energy-Efficient Economy, vol. 3, pp.47-55,1997.

[2] S. G. Niu, "Research on problems of saving electric energy in university laboratory," Journal of Yellow River Conservancy Technical Institute 4 pp. 47-49,2009.

[3] T. Kim, C. Manzie , H. Watson, "Fuel Economy Benefits of Look Ahead Capability in a Mild Hybrid Configuration," Proc. of the 17th IFAC World Congress 8, pp.5646-5651,2008.

[4] C. Manzie, H. Watson, S. Halgamuge, "Fuel Economy Improvements for Urban Driving: Hybrid vs. Intelligent Vehicles," Transportation Research Part C: Emerging Technologies 15, pp. 1-16,2007.

[5] C. H. Zheng, N. W. Kim, S. W. Cha, "Optimal Control in the Powe Management of Fuel Cell Hybrid Vehicles," International Journal of Hydrogen Energy, vol. 37, pp. 655-663,2012.

[6] C. Manzie, T. S. Kim, R. Sharma, "Optimal Use of Telemetry by Parallel Hybrid Vehicles in Urban Driving," Transportation Research Part C: Emerging Technologies, pp. 25, pp. 134-151,2012.

[7] D. V. Ngo, T. Hofman, M Steinbuch., A. F. Serrarens, "An Optima Control-based Algorithm for Hybrid Electric Vehicle using Preview Route Information," Proc. of American Control Conference (ACC) , pp. 5818-5823,2010. 